\title{
Imperatives are existential modals: Deriving the strong reading as an implicature *
}

\author{
Despina Oikonomou \\ Massachusetts Institute of Technology
}

\begin{abstract}
The variety in the interpretation of imperatives has received different accounts in the literature (Wilson \& Sperber 1988; Han 2000; Schwager 2006; Kaufmann 2012; Portner 2007; Grosz 2011; Condoravdi \& Lauer 2012; von Fintel \& Iatridou To appear). In this paper, I argue that imperatives involve an existential modal. I present evidence for the existential analysis of the imperative operator from scopal ambiguities with only. The universal reading is explained on the basis of two factors; i) lack of a scalar counterpart as opposed to overt modals (cf. Deal 2011) ii) strengthening via an implicature derived in the presence of certain focus alternatives (cf. Schwager 2005, 2006; Kaufmann 2012).
\end{abstract}

Keywords: imperative, modality, quantifier scope, implicature

\section{Introduction}

The variety of meanings found in imperatives has been a long-lasting puzzle in the literature (Wilson \& Sperber 1988; Han 2000; Schwager 2006; Kaufmann 2012; Portner 2007; Grosz 2011; Condoravdi \& Lauer 2012; von Fintel \& Iatridou To appear). The same imperative can get different interpretations depending on the context. For example, an imperative like 'Open the window.' can be interpreted as command/request uttered by a teacher when he enters the classroom, or as permission in a context where it is generally prohibited to open the windows during the class but the teacher provides permission after many students have asked for it.

The common strategy in the literature is to suggest an analysis that captures the command/request interpretation (along with other readings which we will not discuss here, e.g. plea, advice, threat, wish) (Schwager 2006; Portner 2007), and introduce a special mechanism in order to derive permission readings.

* I am grateful to Sabine Iatridou, Irene Heim, Kai von Fintel and Edward Flemming for extensive discussions and insightful comments at various stages of this work. For valuable feedback, I would also like to thank the LFRG audience at MIT, six anonymous SALT reviewers, many participants at SALT 26, the SALT editors, Itamar Kastner, Paul Marty, Giorgos Spathas and Vina Tsakali. All errors are, of course, my own. 
In this paper, I go the opposite way; I argue that imperatives are modalized propositions (Schwager 2006; Kaufmann 2012) which involve an existential modal and therefore the permission interpretation is derived for free. The universal reading is derived on the basis of two factors: i) lack of a stronger scalar counterpart as opposed to overt modals (Deal 2011) and ii) strengthening via an implicature derived in the presence of certain focus alternatives. Independent evidence for the existential character of the operator in imperatives is provided by scope interactions of the imperative operator with only.

The following section presents a brief overview of two different analyses of imperatives which capture in different ways command vs. permission readings. In Section 3, I introduce a different approach which treats imperatives as involving an existential modal. In Section 4, I provide evidence for the existential character of imperatives from scope ambiguities with only focusing on Greek. In Section 5, I show how we can derive the strong reading as an implicature. Section 6 concludes and posits some further questions.

\section{Previous analyses of imperatives}

In this section, I present how the different analyses explain the variety of interpretations in imperatives focusing on the distinction between the permission and the command/request interpretation. Broadly we can distinguish between two types of approaches; the minimal approach according to which there is no modal operator present in imperatives and the modal approach which assumes that there is a modal operator in the semantics.

\subsection{Minimal approach}

The essence of the minimal approach is that there is no operator in the semantics of an imperative clause (Portner 2004, 2007; Pak, Portner \& Zanuttini 2008; Mastop 2005; von Fintel \& Iatridou To appear; Starr 2011; Roberts To appear). An imperative clause denotes a property or a proposition. The 'directive' force of imperatives comes from the pragmatics.

Portner $(2004,2007)$ suggests that the imperative is a different clause type along with declaratives and interrogatives. Following the Stalnakerian notion of Common Ground (CG), declaratives serve as updates of the information in the CG. Portner suggests a parallel function for imperatives; imperatives add properties to another stack dubbed To-Do List for each addressee (A). The denotation of the imperative is just a property which holds of the addressee, as shown in (1) for an imperative clause like 'Open the window'.

(1) $\llbracket$ Open the window $\rrbracket=\lambda$ w. $\lambda \mathrm{x}: \mathrm{x}=$ Addresse. $\mathrm{x}$ opens the window in $\mathrm{w}$ 
Imperatives are existential modals

Similarly to the way in which a declarative proposition adds its content to the Common Ground (CG), and interrogatives to the Question Stack (Q), a successfully uttered imperative adds its content to A's To-Do List (T). The following formalization is suggested in Portner 2007:

Pragmatic Function of imperatives

a. The To-Do List function $\mathrm{T}$ assigns to each participant a in the conversation a set of properties $\mathrm{T}(\mathrm{a})$

b. The canonical discourse function of an imperative clause $\phi_{\text {imp }}$ is to add $\llbracket \phi_{\text {imp }} \rrbracket$ to $\mathrm{T}$ (addressee). Where $\mathrm{C}$ is a context of the form $\langle\mathrm{CG}, \mathrm{Q}, \mathrm{T}\rangle$ :

$$
\left.\mathrm{C}+\phi_{\text {imp }}=\langle\mathrm{CG}, \mathrm{Q}, \mathrm{T}[\text { addressee/T(addressee })] \cup \llbracket \phi_{\text {imp }} \rrbracket\right\rangle
$$

In addition, the To-Do List imposes an ordering on the worlds compatible with the CG as shown in (3a). The Agent's commitment principle in (3b) guarantees that the addressee will try to fulfill as many properties as he can from his To-Do List.

Ordering pragmatics for imperatives

a. Partial ordering of worlds: For any $\mathrm{w}_{1}, \mathrm{w}_{2} \in \cap \mathrm{CG}$ and any participant $i, \mathrm{w}_{1}<_{\mathrm{i}} \mathrm{w}_{2}$ iff for some $\mathrm{P} \in \mathrm{T}(i), \mathrm{P}\left(\mathrm{w}_{2}\right)(i)=1$ and $\mathrm{P}\left(\mathrm{w}_{1}\right)(i)=0$, and for all $\mathrm{Q} \in \mathrm{T}(i)$ : if $\mathrm{Q}\left(\mathrm{w}_{2}\right)(i)=1$, then $\mathrm{Q}\left(\mathrm{w}_{1}\right)(i)=1$.

b. Agent's commitment: For any participant $i$, the participants in the conversation mutually agree to deem $i$ 's actions rational and cooperative to the extent that those actions in any world $\mathrm{w}_{1} \in \cap \mathrm{CG}$ such that $\mathrm{w}_{1}<_{\mathrm{i}} \mathrm{w}_{2}$.

Crucially, permission readings posit a problem for this analysis. Portner acknowledges this problem and he suggests a special treatment of permissions in Portner 2010. In a nutshell, the idea is that permission readings arise from conflicting requirements on the To-do List (Portner 2010). Building on the general idea that permissions arise "in the context of a countervailing prohibition" (Kamp 1979), Portner argues that the context in which an imperative is interpreted as a permission typically contains a prohibition. Permission readings arise in contexts in which the updated To-Do List is inconsistent (e.g. take an apple / $\neg$ take an apple) and therefore, there is no preference over the one or the other option (see Portner 2010). A problem with this analysis, as noted in von Fintel \& Iatridou To appear, is that conflicting requirements do not always suggest that there is a possibility of choosing among them. Portner (2010), himself, also acknowledges a similar problem in the following example:

(4) Bring beer to the party tomorrow! Actually, bring wine!

The imperatives in (4) are inconsistent but they do not provide a real choice to the addressee as to whether he brings wine or beer. In order to solve this problem, Portner 
suggests that an imperative can signal a choice among conflicting requirements only when it is marked as permission. In other words the default is that imperatives are interpreted as requirements but in some cases imperatives can be marked (by intonation, or by an overt expression like if you want, or by a morpheme in some languages) as permissions. However, as von Fintel \& Iatridou (To appear) point out, this mechanism abandons the core component of the minimal approach, that there is no feature in semantics indicating permission or requirement (see von Fintel \& Iatridou To appear for discussion and a suggested amendment to Portner's analysis). Below I briefly outline Kaufmann's proposal which is my point of departure for the analysis I pursue.

\subsection{Modal approach}

The common thread in modal analyses of imperatives is that they incorporate a modal operator into the semantics of an imperative clause (Han 2000; Schwager 2006; Kaufmann 2012; Grosz 2011; Condoravdi \& Lauer 2012). Schwager (2006)/ Kaufmann (2012) argues that there is a universal modal operator whereas Grosz (2011) argues in favor of an ambiguity analysis under which imperatives sometimes involve a possibility and sometimes a necessity modal. Condoravdi \& Lauer (2012) develop a different analysis under which the operator in imperatives encodes effective preferences. Here we focus mostly on Kaufmann's analysis.

Kaufmann, in Schwager 2006 and Kaufmann 2012, analyses the imperative operator as a universal modal. Under this approach the meaning of an imperative is identical to that of a proposition containing a universal modal as shown in (5):

(5) $\llbracket$ Open the window $\rrbracket^{w}=\forall \mathrm{w}^{\prime} \in \cap \mathrm{f}(\mathrm{w})$ [A opens the window in $\left.\mathrm{w}^{\prime}\right]$

The fact that there is a modal operator in the semantics allows Kaufmann to use the machinery introduced by Kratzer (1981) in order to account for the variety of interpretations in imperatives. Roughly, by employing different conversational backgrounds for the ordering source, Kaufmann derives wishes ( $g=$ what the speaker wants), requests/commands ( $g=$ what the speaker orders) and advice ( $g$ $=A$ 's preferences, or what is considered to be generally preferred) (see Kaufmann 2012, Section 4.1). However, permission and acquiescence readings once more present a puzzle because it is not a matter of a variable ordering source but of weaker force.

Particularly puzzling for Kaufmann are what she calls for-example imperatives such as the example in (6) which can be an answer to a question like 'How could I save money?'

(6) Stop buying cigarettes for example!

For example-Advice 
Imperatives are existential modals

For cases like this, Kaufmann suggests that the universal modal should be reduced to an existential one. The mechanism she suggests is of particular interest for the analysis I pursue here because, in some sense, it provides a mirror picture of the mechanism I propose. Kaufmann analyses examples like (6) as inexhaustive possibilities. This means that she considers the default imperative as an instance of exhaustive possibility. Below is an example of hers with an overt existential modal that intuitively constitutes an instance of an exhaustive possibility:
A. What could I possibly do to stop smoking?
B. The only thing you can do is stop buying cigarettes.

Building on Zimmermann 2000, Kaufmann shows that an exhaustified possibility amounts to a necessity. Under this idea, an imperative is treated as a possibility which is obligatorily exhaustified thus being equivalent to a necessity:

$$
\operatorname{EXH}(\diamond)=\lambda \mathrm{b} . \lambda \mathrm{p} . \diamond(\mathrm{b})(\mathrm{p}) \&(\forall \mathrm{q} \in \diamond(\mathrm{b}))[\mathrm{q} \in \diamond(\mathrm{p})]=\square
$$

(Kaufmann 2012: 185)

Kaufmann (2012) treats the EXH-operator as being part of the semantics, modifying the modal operator. The question is then what blocks exhaustification in the for-example uses in which we get a possibility reading. She argues that expressions like for-example act as anti-exhaustifiers, thus removing the EXH-operator and licensing a possibility reading. As Kaufmann herself points out the nature of this exhaustive operator as well as the conditions under which anti-exhaustification occurs require further investigation.

The idea I pursue here is, in fact, very similar to Kaufmann's idea of exhaustified possibilities. The difference lies in that I take this exhaustification operator to be the result of the general mechanism in the generation of implicatures in the presence of alternatives. Under this view, exhaustification will apply when there are certain alternatives which depend on the focus-marking. I start off with a possibility modal to explain permission readings and then I show how exhaustification applies to derive the stronger command, request readings.

\section{An existential analysis of imperatives}

The analysis I pursue here can be classified under the modal approaches, since I argue that there is a modal operator in the semantics. Unlike Kaufmann however, I analyse the imperative operator (Imp) as an existential modal.

For the purposes of this paper it suffices to assume that the imperative operator is a bouletic (relativized with respect to the speaker's desires) modal operator with the bouletic component hardwired into its meaning. In particular, the denotation 
of Imp is evaluated with respect to a world $w$ (type $s$ ) and a context $c$, which is a tuple containing the speaker and the addressee $(c:\langle S, A\rangle)$. Imp takes as its argument a proposition $q$ of type $\langle s t\rangle$ and it states that there is a world w' compatible with Speaker's desires in $w$ and $q$ is true in world w'. In other words, (9) says that $q$ is consistent with the speaker's desires.

$\llbracket \operatorname{Imp} \rrbracket^{w, c}=\lambda q \in \mathrm{D}_{\langle s t\rangle} . \exists w^{\prime} \in \mathrm{W}$ such that $S_{c}$ 's desires in w with respect to the $A_{c}$ 's actions are satisfied in $\mathrm{w}^{\prime} \& \mathrm{q}\left(\mathrm{w}^{\prime}\right)=1$

The idea that the flavor of the imperative operator is bouletic, about the speaker's desires, is not new (see Wilson \& Sperber 1988) and it is more recently developed by Condoravdi \& Lauer who analyse imperatives as involving an operator encoding effective preferences.

The crucial question that any modal approach to imperatives faces is how we get from the meaning in (9) to the performative character of imperatives. In other words, how do we explain the fact that imperatives cannot be challenged as lies? Kaufmann, in a series of works (Schwager 2006; Kaufmann 2012, 2016), develops an account of the performativity of imperatives arguing that the modal operator is restricted by certain presuppositions to occur only in contexts which derive a performative interpretation. I will not elaborate more on this part here as it is not directly relevant to the point I want to make regarding the existential quantificational force but I will assume that Kaufmann's account of performativity can be extended to the present analysis.

That said, the meaning for an Imperative like 'Open the window!' is provided in (10):

(10) $\llbracket$ Open the window $\rrbracket^{w, c}=\exists w^{\prime} \in \mathrm{W} . S_{c}$ 's desires in w are satisfied in $\mathrm{w}^{\prime} \wedge A_{c}$ opens the window in $\mathrm{w}^{\prime}$

Whereas this meaning can capture permission readings without any additional assumptions, it cannot account as such for commands/requests, which are usually considered to be the default readings of imperatives. ${ }^{1}$ Before proceeding to an

1 A major argument against an existential approach to imperatives is the ban on the conjunction of conflicting imperatives (von Fintel \& Iatridou To appear: 71):

(11) a. \#Go left and go right! I don't care.

b. You could go left and you could go right. I don't care.

c. Go left. Go right! I don't care.

While an existential analysis accounts for (11c), the data in (11a) remain problematic in view of the well-formedness of (11b). Notice that the data are also problematic for a universal approach, since conjunction of two conflicting requirement is in principle possible (e.g. I want you to leave and I want you to stay.). I believe that the infelicity of $11 \mathrm{a}$ is due to the performative character of imperatives and not due to their quantificational force. Further investigation of performatives is 
Imperatives are existential modals

account for these cases in Section 5, I provide evidence for the existential character of the modal in the next section.

\section{Evidence for the existential character of imperatives from scope ambigui- ties}

Haida \& Repp (2012) observe that an Imperative containing only as in (12) is ambiguous; in context A, we get the reading that it's O.K. to not paint the other tables whereas in context $\mathrm{B}$, we get the reading that it's O.K. to paint the round table but it's not O.K. to paint the other tables:

\section{Context A}

You've asked me to paint those tables but I'm really tired and don't feel like doing something really useful today.

\section{Context B}

Oh, I feel like doing something really useful today. I think I'll paint the tables over there.

(12) Only paint the round table.

(Haida \& Repp 2012: 308)

I argue that the ambiguity in (12) is best explained as a scopal ambiguity. ${ }^{2}$ Evidence for this comes from Modern Greek, where overt focus movement is shown to resolve scope ambiguities. Building on the Greek data with movement, I argue that the ambiguity can be explained only if we treat the imperative modal operator as an existential modal. As I show below, imperatives behave just like overt existential modals with respect to scope ambiguities with only.

\subsection{Evidence from overt movement in Greek}

Overt focus movement in Greek seems to resolve scopal ambiguities in general (cf. Tsimpli 1995, Gryllia 2009). What is of special interest here is the way in which focus movement can affect scope relations between the focused constituent and quantifiers in the sentence. Baltazani (2002) shows that focus is relevant for the scope readings we get, showing that in general a focused constituent takes wide scope. However, she does not discuss cases where the focused constituent is associated with a focus operator like only. Here we are dealing with these cases, showing that overt movement of the only-phrase results in wide scope of only.

necessary in order to understand the data in (11). See Oikonomou (2016) for a discussion.

2 Haida \& Repp (2012) do not consider this to be a scopal ambiguity. The purpose of their paper is to evaluate Portner's and Schwager's account for imperatives in view of what they predict for the particular example. Notice, however, that in footnote (1) Haida \& Repp mention the possibility for the ambiguity to be scopal. 
Consider the following pairs with the overt existential modal in Greek, boris 'can', embedded under the same contexts A\&B introduced by Haida \& Repp (2012). When only appears with its associate in-situ (13a), the sentence is ambiguous and therefore it is felicitous under both contexts. ${ }^{3}$ When the only-phrase is preverbal (13b) only the wide scope (only $>$ can) survives and therefore the sentence is good only under context $\mathrm{B}$. The sentence can only mean that the only table that the addressee is allowed to paint is the round one (e.g. it's not O.K. to paint the other tables).

$$
\begin{aligned}
& \text { a. Boris na vapsis [mono to strogilo trapezi]. } \\
& \text { can.2SG SUBJ paint.2SG only the round table. } \\
& \text { 'You can paint only the round table' } \\
& \rightarrow \text { OK in Context A: } \diamond>\text { only } \\
& \rightarrow \text { OK in Context B: only }>\diamond \\
& \text { b. [mono to strogilo trapezi] boris na vapsis. } \\
& \text { Only the round table can.2SG SUBJ paint.2SG } \\
& \text { 'The only table you can paint is the round one.' } \\
& \rightarrow \text { Bad in Context A: } * \diamond>\text { only } \\
& \rightarrow \text { OK in Context B: only }>\diamond
\end{aligned}
$$

The imperative operator interacts with only exactly in the same way that an existential modal does. In (14a), when the only-DP remains in situ, both the narrowscope $(\operatorname{Imp}>$ only $)$ and the wide-scope $($ only $>\operatorname{Imp})$ reading is available. This is shown by the fact that (14a) is good under both contexts, just like the English example in (12). On the contrary, in (14b) where the only-DP undergoes focus movement only the wide-scope reading where only takes scope above the imperative operator survives. As we can see, (14b) is felicitous only in Context B yielding the interpretation that $A$ is not allowed to paint the other tables:

\section{Context A}

You've asked me to paint those tables but I'm really tired and don't feel like doing something really useful today.

\section{Context B}

Oh, I feel like doing something really useful today. I think I'll paint the tables over there.

$$
\begin{aligned}
& \text { a. Vapse [mono to strogilo trapezi]. } \\
& \text { Paint only the round table. } \\
& \rightarrow \text { OK in Context A: } \diamond>\text { only } \\
& \rightarrow \text { OK in Context B: only }>\diamond
\end{aligned}
$$

3 See Crnič (2013) for independent evidence for the availability of inverse scope of only with modal operators. 
Imperatives are existential modals

$$
\begin{aligned}
& \text { b. [mono to strogilo trapezi] vapse. } \\
& \text { Only the round table paint. } \\
& \rightarrow \text { Bad in Context A: } * \diamond>\text { only } \\
& \rightarrow \text { OK in Context B: only }>\diamond
\end{aligned}
$$

The scope ambiguity is not specific to the interaction with only, it is also attested with degree quantifiers such as few, fewer than. ${ }^{4}$ (15a) in which few surfaces in-situ is felicitous in both Contexts A \& B, whereas (15b), where few has undergone overt movement, is only compatible with Context B. When few is interpreted below Imp, the interpretation is that $A$ is allowed to paint few tables (and it is O.K. to not paint all of them) whereas when few takes wide scope the interpretation is that there are few tables that the A is allowed to paint (the rest of them he is not allowed to paint):

a. Vapse liga trapezia!

Paint few tables

$\rightarrow$ OK in Context A: $\diamond>$ only

$\rightarrow$ OK in Context B: only $>\diamond$

b. Liga trapezia vapse!

few tables paint

$\rightarrow$ Bad in Context $\mathrm{A}: *_{\diamond}>$ few

$\rightarrow$ OK in Context B: few $>\diamond$

In the following, I show that the scope ambiguity can be derived assuming that the imperative operator has existential as opposed to universal force, which derives the wrong meaning. If there is no operator at all, it becomes impossible to account for the scope interaction with overt movement.

\subsection{Deriving the scope ambiguity}

For the purposes of the discussion here, I follow a version of Horn's (2011) analysis of only as a presupposition trigger; only takes as its argument a proposition $p$, presupposes that $p$ is true and asserts the negation of all alternatives of $p$. Following Rooth (1992), the alternatives of $p$ are computed by substituting the focused constituent ROUND with the relevant alternatives (i.e. SQUARE/TRIANGLE). Given these assumptions, when only has narrow scope, it will attach to the prejacent (below the modal operator) yielding the LF in (16a) and the corresponding alternatives ( $A$ paints the round/square/triangle table). When only has wide-scope, it merges above the modal operator, deriving the LF in (16b) and the alternatives that $\exists w^{\prime} \in \mathrm{W}$. $S$ 's desires in $\mathrm{w}$ are satisfied in $\mathrm{w}^{\prime} \wedge A$ paints the ROUND/SQUARE/TRIANGLE table in $\mathrm{w}^{\prime}$ :

4 Thanks to a SALT reviewer and to Irene Heim for pointing out the relevance of these data. 
(16) a. $\operatorname{LF}\left(\diamond>\right.$ only): $\left[\diamond_{\text {imp }}\left[\left[\operatorname{only}(\mathrm{C}) \operatorname{round}_{F}\right.\right.\right.$ table $][\lambda x$ [you paint $\left.\left.\left.x]\right]\right]\right]$

b. $\operatorname{LF}($ only $>\diamond):\left[\operatorname{only}(\mathrm{C}) \operatorname{round}_{F}\right.$ table] $\left[\lambda x\left[\diamond_{\text {imp }}\right.\right.$ [you paint $\left.\left.\left.x\right]\right]\right]$

Based on this, when only is interpreted below the existential modal (Context A), we get the meaning in (17a) that there is a world consistent with S's desires and A doesn't paint the square/triangle table in this world. When only takes scope above the existential modal (Context B), we get the interpretation in (17b) that there is no world consistent with $S$ 's desires in which A paints the square/triangle table:

a. $\exists w^{\prime} \in \mathrm{W} . S^{\prime} s$ desires in $\mathrm{w}$ are satisfied in $\mathrm{w}^{\prime} \wedge \neg[A$ paints the SQR/TRG table in $\left.\mathrm{w}^{\prime}\right]$

$\rightarrow A$ is allowed to not paint the other tables.

b. $\neg \exists w^{\prime} \in \mathrm{W}$. $S$ 's desires in $\mathrm{w}$ are satisfied in $\mathrm{w}^{\prime} \wedge A$ paints the SQR/TRG table in $\mathrm{w}^{\prime}$

$\rightarrow A$ is not allowed to paint the other tables.

The data from Greek show that when the only-DP overtly moves, we get a wide scope reading and the interpretation derived can only be explained if there is a covert existential operator. As I show below, a universal or an ambiguous analysis of the imperative operator cannot account for the data presented.

\subsection{Scope facts under a universal analysis of $\operatorname{Imp}$}

Under a universal analysis of the modal operator, we can derive the expected interpretation for the examples in which only is in-situ, but we derive the wrong reading for the examples in which the quantifier moves overtly. When only surfaces in-situ both readings are licensed for context A \& B as shown in (18):

Vapse mono to strogilo trapezi!

Paint only the round table

$\rightarrow \square>$ only: A is required not to paint the other tables.

$\rightarrow$ only $>\square:$ A is not required to paint the other tables.

When the only-phrase moves only wide scope (only $>\square$ ) is expected to survive. However, this would predict the wrong interpretation under Context B (Oh, I feel like doing something really useful today. I think I'll paint the tables over there.), because we derive the interpretation that that $A$ is not required to paint the other tables, whereas the desired interpretation is that $A$ is required to not paint the other tables.

Similarly, under an ambiguous analysis of imperatives (Grosz 2011), we would expect two possible readings for the example with overt focus movement: 
Imperatives are existential modals

[mono to strogilo trapezi] vapse!

Only the round table paint!

$\rightarrow$ only $>\square:$ A is not required to paint the other tables.

$\rightarrow$ only $>\diamond: A$ is not required to paint the other tables.

The absence of the reading in which only has wide scope above a universal modal suggests that the modal can only have an existential interpretation here. Unless there is some strange condition under which overt movement blocks the universal reading, it is hard to explain the interpretation of (19) assuming an ambiguity analysis.

\subsection{Scope facts under a minimal approach}

Under the minimal approach in which there is no operator in the semantics, it is not possible to explain the facts as a scope ambiguity. Haida \& Repp (2012) attempt to explain the ambiguity of the English data not as a scope ambiguity but as an ambiguity which arises by the imperative being interpreted as command or permission. However, the Greek data show that the ambiguity is scopal in nature.

The only solution would be to postulate a speech act operator (something that would be closer to Portner's approach but still an operator in the semantics). In this case however, it is under question whether only could scope as high as a speech act operator (see Krifka 2001 for which operators can scope above a speech act operator).

To summarize, the scope facts in Greek, where overt focus movement resolves scope ambiguities, provide solid evidence in favor of a covert existential modal in imperatives and against a universal or a minimal approach. The existential approach not only handles permission readings without any additional assumptions but it is also independently motivated by the observed scopal ambiguities. The main question is how the strong readings (command, request) are derived, which I address in the next section.

\section{Deriving the strong-reading}

It is clear that a possibility modal does not capture the imperative meanings in (20):

a. Translate this document!

Command

b. Give me some chocolate!

Plea

c. Open the door, please!

Request

d. Be at home!

Wish

The idea I pursue here is that in all of these imperative clauses there is an existential modal which is strengthened to a universal modal. Below I discuss the conditions under which strengthening happens. 
Oikonomou

\subsection{Conditions for strengthening}

\subsubsection{Condition I: Lack of a stronger scalar counterpart}

First, for a stronger interpretation to arise, a necessary condition is that this interpretation is not blocked. We know for example, that overt possibility modals cannot be strengthened. The sentence in (21) cannot mean 'You must open the door.'

(21) You can open the door.

This is explained as a conversational scalar implicature which is derived considering the fact that the Speaker didn't use the stronger scalar counterpart to the existential modal, the universal modal must ${ }^{5}$ The exact mechanism for the derivation of the implicature varies depending on the theory one favors. For now, it is not important whether one favors a pragmatic (neo-Gricean approach: Spector 2007; van Rooij \& Schulz 2004; Sauerland 2004; Chemla 2008) or a grammatical (Chierchia 2006, 2013; Chierchia, Fox \& Spector 2009, 2012; Fox 2007) view for the derivation of scalar implicatures. For ease of exposition, I will stick to the grammatical approach as outlined in Chierchia et al. 2009.

Under this approach, there is an Exhaustivity operator (EXH) that negates the alternatives and is responsible for the generation of the implicature. The EXHoperator states that the proposition $\mathrm{S}$ is true and that the only members of the set of alternatives (ALT) that are true are those entailed by S (Chierchia et al. 2009: 4). The formal definition is given in (22):

$$
\llbracket \operatorname{EXH}_{A L T}(\mathrm{~S}) \rrbracket^{w}=1 \text { iff } \llbracket \mathrm{S} \rrbracket^{w}=1 \text { and } \forall \phi \in \operatorname{ALT}(\phi(\mathrm{w}))=1 \rightarrow(\llbracket \mathrm{S} \rrbracket \subseteq \phi)
$$

The alternatives in the case of the example in (21) will be the propositions derived by substituting can with its horn-scalemate must. By applying EXH to the alternatives, we derive the implicature that it's not the case that A must open the window.

Now the question is why imperatives don't give rise to a similar implicature, since we analysed them as possibility modals. I propose that no such implicature arises because the imperative operator does not have a stronger scalar counterpart in the first place. The idea that there are existential operators which lack a stronger scalemate is not a new one. In the domain of modality, Deal (2011) suggests that modal suffixes in Nez Perce are existential in character but they are not part of the Horn scale, they don't have a stronger counterpart. According to Deal (2011) the

5 In some specific contexts such as a queen-servant-context in which a queen tells her servant 'You may leave now', the utterance can be understood as a command rather than permission. Given the exceptional character of these environments, they will not concern us here. For all the other cases with overt possibility modals, I will assume that the scalar implicature is always present, therefore blocking a stronger interpretation. 
Imperatives are existential modals

absence of an implicature is a key-point in explaining why these suffixes can be used in contexts where a universal modal could appear. This idea gains ground in explaining other instances of quantifiers with apparently ambiguous force. For example, Bowler (2014) argues that in Walpiri there is a disjunction operator which lacks a conjunction counterpart and therefore, in some environments, it can be strengthened to a conjunction operator. Bar-Lev \& Margulis (2014) argue that a quantifier kol in Hebrew is existential in nature but it lacks a stronger counterpart and therefore it can be interpreted as universal. A similar idea is employed by Bassi \& Bar-Lev (2016) in order to explain the mixed behavior of bare conditionals. The idea I employ here is essentially the same, the imperative operator does not have a stronger scalar counterpart and therefore we can get a stronger interpretation.

\subsubsection{Condition II: Exhaustifying over focus alternatives}

The next step is to explain what forces the necessity reading. I argue that strengthening is the result of an implicature derived by exhaustifying over certain focus alternatives. The command/request readings are derived when the alternatives involve the negation of the prejacent $(\mathrm{p}),(\neg \mathrm{p})$. I argue that this happens when the prejacant is broadly focused.

Following Rooth (1992), the alternatives of $\mathrm{p}$ can be any proposition of type $\langle s t\rangle$. When an imperative $\left(\diamond_{\text {imp }} \mathrm{p}\right)$ is uttered in an out-of-the-blue context I take the only contextually salient proposition to be the negation of $\mathrm{p},(\neg \mathrm{p})$, thus deriving the alternatives in (24) for the imperative in (23):

Open the window!

$$
\left.\begin{array}{l}
\left\{(23) \rrbracket^{f, w}=\right. \\
\exists w^{\prime} \in \text { W. S's desires in w are satisfied in } \mathrm{w}^{\prime} \wedge A \text { opens wnd in } \mathrm{w}^{\prime} \\
\exists w^{\prime} \in \text { W. S's desires in w are satisfied in } \mathrm{w}^{\prime} \wedge \neg\left[A \text { opens wnd in } \mathrm{w}^{\prime}\right]
\end{array}\right\}
$$

The focus alternatives are then evaluated by the ExH-operator, introduced above, and all non-weaker alternatives are negated, thus deriving the implicature in (25):

$$
\neg \exists w^{\prime} \in \text { W. S's desires in w are satisfied in } \mathrm{w}^{\prime} \wedge \neg\left[A \text { opens wnd in } \mathrm{w}^{\prime}\right]
$$

By exhaustifying the alternatives we get the interpretation that there is no world compatible with S's desires in which A does not open the window. This is equivalent to saying that $A$ must open the window, thus capturing the strong-reading of the imperatives when they are intended as commands, requests, etc. The reader can see now how this analysis presents the mirror picture of the analysis presented in Kaufmann 2012. For her, the imperative operator is a universal modal composed from an existential modal and an Exhaustive operator (EXH). In some specific contexts 
(for-example-advice) EXH is removed and therefore, a possibility reading arises. In the present analysis, imperatives involve just a possibility modal. Exhaustification applies in certain environments upon the emergence of focus alternatives.

The critical question that we have to address under the present analysis is how a negated (and therefore more complex) form is licensed as an alternative. Under Rooth's mechanism for the derivation of the alternatives, we would expect any proposition of type $\langle s t\rangle$ to be a vital alternative to $\mathrm{p}$. This means that when a speaker utters an imperative such as 'Open the window!' we could derive an infinite set of alternatives including 'Play the guitar.', 'Swim.', etc. Indeed, when the context provides a relevant set of possibilities then EXH can exhaustify over these possibilities, as suggested in Kaufmann 2012. For example, imagine a context in which an entrepreneur is faced with bankruptcy and he has three ways in which he can avoid this; selling his house, getting a new loan or marry his main opponent. In this context, his father utters the Imperative in (26):

\section{(26) Marry your opponent.}

In this context, we should definitely consider 'sell the house' and 'get a new loan' as vital alternatives which will be exhaustified, deriving the interpretation that there is no world compatible with the Speaker's desires in which the addressee sells his house or gets a new loan. In this case, we don't even need the negated alternative $\neg$ marry your opponent. But what about cases, in which an imperative is uttered in an out-of-the-blue context? What if the context provides no other possibilities?

In cases in which an imperative is uttered without any relevant preceding context, it seems that we want the only relevant alternative to be the negation of the prejacent and not to exhaustify blindly over an infinite set of possibilities to derive a strong interpretation. Consider, for example, a case in which a mother returns from work and she says to her kids 'By tomorrow clean your rooms.' By uttering this, the mother doesn't exclude other things that the kids are allowed to do, she only tells them that it's necessary to clean their rooms. This can be captured if we take the alternative to be derived by substituting the prejacent with its negation. So far, so good, but although the claim that the alternative is derived by substituting $p$ with its negation is compatible with Rooth's original analysis, it runs into problems when we consider the broader picture of alternatives computation.

Fox \& Katzir (2011) suggest a theory for the Computation of Alternatives which does not allow alternatives which are structurally more complex than their prejacent. Clearly, the negation of a proposition $\mathrm{p}$ is structurally more complex than $\mathrm{p}$. Fox \& Katzir's analysis provides a solution to a more general problem, the symmetry problem in the computation of implicatures and therefore we don't want to discard their theory. However, there is a way out of this problem. In the definition for the calculation of alternatives, Fox \& Katzir allow more complex alternatives as long as 
Imperatives are existential modals

they are imposed by the context as relevant alternatives. I argue that the negation of a proposition $p$ is always a contextual salient alternative when $p$ is broadly focused. This not only allows us to derive the right meaning for strong imperatives but it also captures the intuition that, in some cases, an imperative expresses a preference between $p$ and $\neg p$ (cf. Condoravdi \& Lauer 2012; Starr 2011).

\subsection{The role of prosody}

The claim that strengthening depends on focus alternatives predicts that the prosodic pattern of an imperative clause is directly associated with the reading that we get. Indeed, this is a broader claim put forward by the present analysis. Although, the space is limited to set up such an analysis here, let me at least provide some cues that indeed focus (F-)marking becomes relevant for the interpretation of imperatives.

Firstly, I assumed in the previous section that a strengthened meaning arises when an imperative is broadly focused. Broad focus in imperatives, similarly to declaratives, is marked with a Nuclear Pitch Accent (NPA) on the right-edge of the utterance. This predicts that an imperative which has a distinct prosodic pattern (i.e. narrow focus on some non-final constituent) will not give rise to a strong interpretation. I will discuss here two different cases, one in which the NPA falls on the verb and one in which the NPA falls on a different constituent (narrow focus). I show that in these cases we do not derive a strengthened interpretation at least not the same as in the case of broad focus, suggesting that F-marking plays indeed a significant role in the interpretation of imperatives.

\subsubsection{NPA on the verb $\rightarrow$ permission readings}

In the above contexts, command and permission readings are associated each with a distinct prosodic pattern. Commands/requests are realized with broad focus intonation (the NPA falls on the rightmost constituent) whereas in permission contexts the NPA falls on the verb. NPA accent on the verb is compatible with many possibilities regarding F-marking. For example, we could assume that the verb itself is focused, deriving lexical alternatives such as open, close, etc. However, in the permission contexts this is not the case, normally the VP is already given. Consider the following example in which the imperative is uttered in a context which foregrounds permission:

(27) Context:The rules of the school require that during the class the window remains closed. However, today the kids feel very hot and they ask their teacher to open the window. Then the teacher responds back saying:

O.K. Open the window. But it's your responsibility. 
In this context, the natural way to utter the imperative is with the NPA on the verb followed by de-accenting. I take these cases to be an instance of verum focus, with the covert imperative operator being F-marked. The alternatives derived by focusing the covert operator in an imperative clause like 'Open the window.' will be its negation (verum focus), as shown in (28), therefore no implicature is derived, because the alternative contradicts the assertion.

$$
\left\{\begin{array}{l}
\llbracket(23) \rrbracket^{f, w}= \\
\exists w^{\prime} \in \mathrm{W} . S^{\prime} \text { 's desires in } \mathrm{w} \text { are satisfied in } \mathrm{w}^{\prime} \wedge A \text { opens wnd in } \mathrm{w}^{\prime} \\
\neg \exists w^{\prime} \in \mathrm{W} . S^{\prime} s \text { desires in } \mathrm{w} \text { are satisfied in } \mathrm{w}^{\prime} \wedge A \text { opens wnd in } \mathrm{w}^{\prime}
\end{array}\right\}
$$

The meaning we get is that there is a world compatible with the Speaker's desires in which the addressee opens the window, and no additional implicature is derived which captures our intuition about the weak interpretation of the imperative in this context. Much more is to be said about such cases as well as the role of the context, the interaction between F-marking and givenness but for the sake of space I will not expand here (see Oikonomou 2016). What is important for the scope of the present paper is that a permission reading is indeed associated with a distinct prosodic pattern from the one we find in commands/requests, supporting the idea that a strengthened meaning arises by exhaustifying over focus alternatives. In the following, we discuss cases with narrow focus on a constituent which generate a different implicature, one that doesn't entail necessity.

\subsubsection{Narrow-focus imperatives}

Another possibility is to have narrow focus on a constituent. In this case under the present analysis, we will derive the interpretation that $p$ is compatible with S's desires and that an alternative derived by substituting the focused constituent is not. For example, the imperative in (29) with narrow focus on vanilla provides permission to the kid to eat vanilla ice-cream but it also conveys a prohibition against eating other ice-cream flavors (e.g. chocolate ice-cream):

Context: Child is asking for ice-cream at 10p.m. His mother desperate says: O.k... Eat VANILLA ice-cream!... Although, you shouldn't eat any icecream.

$\rightarrow$ You are not allowed to eat chocolate/brownie/strawberry ice-cream etc.

Of course, narrow focus is also compatible in contexts in which the prejacent is not only taken to be possible but also necessary. For example, in (30) it is already established that a window must be opened and the imperative clause conveys that $A$ can open the front window but not the back window. 
Imperatives are existential modals

(30) Context: It stinks in here.. You should open a window... Open the FRONT window!

$\rightarrow$ You are not allowed to open the back window, etc.

The necessity interpretation in (30) is not problematic for the present analysis because the request/command is already established in the context.

Overall, the present analysis predicts that there is a mapping between the prosodic pattern and the interpretation of the imperative (if not one-to-one correspondence, there is at least differentiation between commands and permissions). Further types of imperatives like advice or wishes should be examined in order to gain a better understanding for the way in which prosody can provide cues for the interpretation of imperatives.

\section{Concluding remarks}

In this paper, I presented an analysis of imperatives as existential modals. I showed that in this way we can account for free for permission readings as opposed to analyses which relate the imperative with a universal modal or with a function that updates the context. Moreover, I showed that an existential analysis is independently motivated by the scope facts presented in Section 4. However, an existential analysis faces the question of how strong meanings of imperatives are derived.

I showed that a command/request interpretation can be derived by the strengthening mechanism we use in computing conversational implicatures. The input to this mechanism is the set of focus alternatives. Of course, we could also imagine different ways of deriving the strengthened interpretation. Another possibility would be to apply exhaustification over domain alternatives as suggested in Bassi \& BarLev 2016 for conditionals and Bar-Lev \& Margulis 2014 for the quantifier kol in Hebrew. However, a strong motivation for deriving the strengthened interpretation by exhaustifying over focus alternatives is that the focus placement appears to be tightly connected to the interpretation of imperatives as we discussed briefly in the previous section. Abandoning the idea of focus alternatives would force us to think of a different way in order to account for the correlation between the prosody and the meaning.

An ultimate question arising from this analysis is whether there is a principled explanation for the existential character of imperatives. Relatedly, we observe that similar constructions to imperatives like root subjunctives in Greek and other languages are also ambiguous between permission and command readings. One idea worth exploring would be to see whether generally covert modals are existential modals which can be strengthened to convey necessity. Notice that conditionals have also been analysed as existential in recent works (Herburger 2015; Bassi \& Bar-Lev 2016). If this is true then maybe we can have a generalization regarding the 
existential character of covert modals.

\section{References}

Baltazani, Mary. 2002. Quantifier scope and the role of intonation in greek. Los Angeles: University of California Los Angeles (UCLA) PhD dissertation.

Bar-Lev, Moshe E. \& Daniel Margulis. 2014. Hebrew kol: A universal quantifier as an undercover existential. In Urtzi Etxeberria, Anamaria Fălăuş, Aritz Irurtzun \& Bryan Leferman (eds.), Sinn und Bedeutung (SuB) 18, 60-76. Bayonne and Vitoria-Gasteiz.

Bassi, Itai \& Moshe E. Bar-Lev. 2016. Existential semantics for bare conditionals and grammatical strengthening. Handout from a talk presented at MIT LFRG on May 4, 2016.

Bowler, Margit. 2014. Conjunction and disjunction in a language without 'and'. In Mia Wiegand Todd Snider, Sarah D’Antonio (ed.), Semantics and Linguistic Theory (SALT) 24, 137-155. LSA and CLC Publications.

Chemla, Emmanuel. 2008. An anti-introduction to presuppositions. In Paul Egré \& Giorgio Magri (eds.), Presuppositions and implicatures: MIT-France workshop on scalar implicature and presupposition 60, MIT Working Papers in Linguistics (MITWPL).

Chierchia, Gennaro. 2006. Broaden your views: Implicatures of domain widening and the "logicality" of language. Linguistic Inquiry 37(4). 535-590.

Chierchia, Gennaro. 2013. Logic in Grammar: Polarity, Free Choice, and Intervention. 2. Oxford University Press.

Chierchia, Gennaro, Danny Fox \& Benjamin Spector. 2009. Hurford's constraint and the theory of scalar implicatures. Presuppositions and Implicatures 60. 47-62.

Chierchia, Gennaro, Danny Fox \& Benjamin Spector. 2012. The grammatical view of scalar implicatures and the relationship between semantics and pragmatics. In Klaus von Heusinger, Claudia Maienborn \& Paul Portner (eds.), Semantics: An International Handbook of Natural Language Meaning 3, 2297-2331. Mouton de Gruyter.

Condoravdi, Cleo \& Sven Lauer. 2012. Imperatives: Meaning and illocutionary force. In Empirical Issues in Syntax and Semantics 9, 37-58.

Crnič, Luka. 2013. Scope fixing and focus movement. Poster presented at Semantics and Linguistic Theory (SALT) 24, 05/2013 https://www.nyu.edu/projects/ salt2014/SALT_2014/Program_files/crnic-salt2014-poster.pdf.

Deal, Amy Rose. 2011. Modals without scales. Language 87(3). 559-585.

von Fintel, Kai \& Sabine Iatridou. To appear. A modest proposal for the meaning of imperatives. In Ana Arregui, Maria Luisa Rivero \& Salanova Andres (eds.), Modality Across Syntactic Categories, Oxford: Oxford University Press. 
Imperatives are existential modals

Fox, Danny. 2007. Free choice and the theory of scalar implicatures. In Uli Sauerland \& Penka Stateva (eds.), Presupposition and Implicature in Compositional Semantics, 71-120. London: Palgrave Macmillan UK. doi:10.1057/9780230210752_4. http://dx.doi.org/10.1057/9780230210752_4.

Fox, Danny \& Roni Katzir. 2011. On the characterization of alternatives. Natural Language Semantics 19(1). 87-107.

Grosz, Patrick. 2011. German particles, modality, and the semantics of imperatives. In Suzi Lima, Kevin Mullin \& Brian Smith (eds.), North East Linguistic Society (NELS) 39, 323-336. Amherst, MA: GLSA.

Gryllia, Stella. 2009. On the nature of preverbal focus in greek: a theoretical and experimental approach. Utrecht: Leiden University $\mathrm{PhD}$ dissertation.

Haida, Andreas \& Sophie Repp. 2012. Only in imperatives. In Guevara Ana Aguilar, Chernilovskaya Anna \& Nouwen Rick (eds.), Sinn und Bedeutung (SuB) 16, 307-320. Utrecht: MIT Working Papers in Linguistics.

Han, Chung-hye. 2000. The Structure and Interpretation of Imperatives: Mood and Force in Universal Grammar. New York and London: Garland Publishing Inc.

Herburger, Elena. 2015. Only if: If only we understood it. In Eva Csipak \& Hedde Zeijlstra (eds.), Sinn und Bedeutung (SuB), 284-301. Göttingen, Germany.

Horn, Laurence. 2011. A presuppositional analysis of 'only' and 'even'. In R.I. Binnick, Alice Davidson, M. G. Green \& J.L. Morgan (eds.), Fifth Regional Meeting of the Chicago Linguistics Society (CLS), 98-107. Chicago, IL: CLS.

Kamp, Hans. 1979. The logic of historical necessity. Unpublished manuscript .

Kaufmann, Magdalena. 2012. Interpreting Imperatives. Berlin: Springer.

Kaufmann, Magdalena. 2016. Fine-tuning natural language imperatives. Journal of Logic and Computation .

Kratzer, Angelika. 1981. The notional category of modality. In Hans J. Eikmeyer \& Rieser Hannes (eds.), Words, worlds, and contexts: New approaches in word semantics, 38-74. Berlin: de Gruyter.

Krifka, Manfred. 2001. Quantifying into question acts. Natural Language Semantics 9(1). 1-40.

Mastop, Rochus Jacobus. 2005. What can you do?: Imperative mood in semantic theory. Amsterdam: Institute for Logic, Language and Computation (ILLC) $\mathrm{PhD}$ dissertation.

Oikonomou, Despina. 2016. Covert modality in root contexts. Cambridge, MA: Massachusetts Institute of Technology (MIT) PhD dissertation.

Pak, Miok D., Paul Portner \& Raffaella Zanuttini. 2008. Agreement in promissive, imperative, and exhortative clauses. Korean Linguistics 14(1). 157175. doi:http://dx.doi.org/10.1075/k1.14.07mdp. http://www.jbe-platform.com/ content/journals/10.1075/k1.14.07mdp.

Portner, Paul. 2004. The semantics of imperatives within a theory of clause types. 
In Robert B. Young (ed.), Semantics and Linguistic Theory (SALT) 14, 235-252. LSA and CLC Publications.

Portner, Paul. 2007. Imperatives and modals. Natural Language Semantics 15(4). 351-383.

Portner, Paul. 2010. Permission and choice. In Günther Grewendorf \& Ede Thomas Zimmermann (eds.), Discourse and Grammar. From Sentence Types to Lexical Categories, 43-68. Mouton de Gruyter (Studies in Generative Grammar).

Roberts, Craige. To appear. Speech acts in discourse context. In Daniel Fogal, Daniel Harris \& Matt Moss (eds.), New Work on Speech Acts, Oxford University Press.

van Rooij, Robert \& Katrin Schulz. 2004. Exhaustive interpretation of complex sentences. Journal of Logic, Language and Information 13(4). 491-519.

Rooth, Mats. 1992. A theory of focus interpretation. Natural Language Semantics 1(1). 75-116.

Sauerland, Uli. 2004. Scalar implicatures in complex sentences. Linguistics and Philosophy 27(3). 367-391.

Schwager, Magdalena. 2005. Exhaustive imperatives. In Paul Dekker \& Michael Frank (eds.), 15th Amsterdam Colloquium, 233-238. Amsterdam: ILLC.

Schwager, Magdalena. 2006. Interpreting imperatives. Frankfurt: University of Frankfurt/Main $\mathrm{PhD}$ dissertation.

Spector, Benjamin. 2007. Scalar implicatures: Exhaustivity and gricean reasoning. In Questions in Dynamic Semantics, 225-249. Brill. http://booksandjournals. brillonline.com/content/books/b9780080470993s011.

Starr, William B. 2011. A preference semantics for imperatives. Manuscript http://williamstarr.net/research/a_preference_semantics_for_imperatives.pdf.

Tsimpli, Ianthi-Maria. 1995. Focusing in modern greek. In Katalin E., Kiss (ed.), Discourse Configurational Languages, 176-206. Oxford University Press Oxford.

Wilson, Deidre \& Dan Sperber. 1988. Mood and the analysis of non-declarative sentences. In Jonathan Dancy, Julius Moravcsik \& Christopher Taylor (eds.), Human Agency: Language, Duty and Value, 77-101. Stanford University Prress.

Zimmermann, Thomas Ede. 2000. Free choice disjunction and epistemic possibility. Natural Language Semantics 8(4). 255-290.

Despina Oikonomou

77 Massachusetts Avenue, 32-D808

Cambridge, MA 02139, USA

despina@mit.edu 